\title{
ARTIGOS
}

\section{A FUNÇÃO TRANSCENDENTAL DO GEMÜT NA CRÍTICA DA RAZÃO PURA}

Valerio Rohden* rohden@via-rs.net

RESUMO O Gemüt(ânimo) é aqui apresentado numa duplaperspectiva: de um lado, como faculdade geral de representações (cf. o quadro ao final do texto) e, de outro, como princípio de unificação das faculdades de conhecimento, especialmente de entendimento e sensibilidade, na Crítica da razão pura. Num e noutro caso, a referência ao Gemüt envolve uma relação aberta do conhecimento com as demais faculdades. É por isso que a razão, sendo vista em analogia com um organismo, articula o conhecimento com um todo humano, que remete à quarta pergunta, introduzida na Lógica, "que é o homem?", à qual podem se reduzir todas as demais. Assim homem e Gemüt se equivalem. O ânimo humano, admitido na Crítica da faculdade do juízo como princípio da vida, sobretudo pela vinculação com o corpo, torna propícia a evocação dos versos de Goethe, que contrapõem teoria e a vida enquanto uma árvore, no primeiro Fausto. Mas não se trataria de opor teoria e vida, como o reconheceu mais tarde o poeta, e sim de redescobrir seu estreito e fecundo vínculo, também no nível da produção do conhecimento humano.

Palavras-chave Ânimo; Transcendental; Conhecimento; Faculdades de representação; Razão; Vida.

ABSTRACT The Gemüt (animus) is presented here in a double perspective: from one side, as a general faculty of representations (see the

* Professor titular da Universidade Luterana do Brasil/ULBRA; Professor visitante da Pontifícia Universidade Católica do Paraná/PUCPR; Professor voluntário da Universidade Federal de Santa Catarina/UFSC; membro do corpo docente de seu Programa de Pós-Graduação em Filosofia. Pesquisador do CNPq. Artigo recebido em jun. 2008 e aprovado em 26 nov. 2008.

KRITERION, Belo Horizonte, no 119, Jun./2009, p. 7-22. 
chart at the end of the text) and, on the other hand, as a principle of unification of the faculties of knowledge, especially understanding and sensibility, in the Critique of Pure Reason. In one or another case, the reference to the Gemüt involves an open ralationship of knowledge with other faculties. That is why the reason, being seen in analogy with an organism, articulates the knowledge with a whole (human), which refers to the fourth question, introduced in logic, "what is man?", to which all the others can be reduced. Thus, man and Gemüt are equivalent. The human soul, admitted in the Critique of judgment faculty as a principle of life, especially by the link with the body, makes propicious the evocation of Goethe's verses, that contrasts theory and life as a tree, in the first Fausto. But is not an opposition between theory and life, as recognized later by the poet, but to rediscover their close and fruitful relationship, also in the production of human knowledge.

Keywords Gemüt; Transcendental, Knowledge; Reperesentation'sfaculties; Reason; Life.

\begin{abstract}
Com referência aos princípios do conhecimento, a razão especulativa pura é uma unidade que subsiste por si de um modo bem peculiar e na qual, como um corpo organizado, cada membro existe em função de todos os demais e todos os demais em função dele, e assim nenhum princípio pode ser tomado com segurança numa relação sem ter sido ao mesmo tempo investigado na sua relação universal com todo o uso puro da razão.
\end{abstract}

(KANT, I. Crítica da razão pura, B XXIII) $)^{1}$

Pretendo mostrar como a partir do simples conceito de Gemüt e a partir de seus troncos e ramos forma-se um todo articulado de conhecimentos chamado ciência, vinculado à ideia de organismo, consequentemente à ideia de vida.

1 Veja-se como esse pensamento, do Prefácio à segunda edição da Crítica da razão pura (1787, abrev.: $\mathrm{KrV})^{*}$, foi antecipado de forma quase literal nos Prolegômenos a toda metafísica futura (1783, abrev.: Prol): "Pois a razão pura é uma esfera tão isolada, tão completamente conectada em si mesma, que não é possível tocar em uma de suas partes sem que se atinjam todas as outras, e nada se pode fazer sem ter determinado a cada parte o seu lugar e sua influência sobre as demais, porque nada a não ser ela poderia corrigir interiormente nosso juízo; a validade e utilidade de cada parte dependem da relação que existe entre ela e as outras na própria razão, e, como acontece na estrutura de um corpo organizado, a finalidade de cada um dos membros só pode ser deduzida do conceito completo do todo. Partindo daí, pode-se afirmar de tal Crítica que ela nunca será digna de confiança, se não estiver integralmente acabada até os mínimos elementos da razão pura, e que, na esfera deste poder, ou se deve determinar e regular tudo ou então nada" (KANT, I. Prolegômenos. São Paulo: Abril, 1980. p. 12).

* As abreviaturas usadas no presente texto seguem a respectiva forma de unificação recomendada pela Kant-Studien Redaktion, a partir da Edição da Academia (Akademie-Ausgabe $=A A)$. 
Vou expor-lhes de início o ponto de partida que leva a essa direção. Por ocasião da tradução da edição B da Crítica da razão pura $(\mathrm{KrV}),{ }^{2} \mathrm{Udo}$ Moosburger e eu adotamos para Gemüt o termo mente. Mais tarde, por ocasião da tradução da Crítica da faculdade do juízo $(K U),{ }^{3}$ António Marques e eu concordamos em traduzir Gemüt por ânimo. Vimos que Kant muitas vezes fornecia em latim e entre parênteses, após o termo Gemüt, os termos animus e mens. Sabemos que esses termos vêm carregados de uma história de sentidos, em virtude da qual a opção por uma tradução ou outra deles envolvia algumas consequências. O próprio Kant, diante da conotação metafísica do termo Seele/anima (alma), passou a preferir em sua concepção crítica, em vez dele, o termo Gemüt/animus (ânimo). Em decorrência de uma investigação da questão, publiquei no início dos anos 1990 um artigo com minha posição a respeito. ${ }^{4}$ Tratou-se de um texto mais abrangente do que este, que pretendo direcionar para a Crítica da razão pura. Então, movendo-me neste espaço da $K r V$, pretendi inicialmente limitar-me ao comentário de duas passagens, na quais Kant explicitamente se manifesta a respeito. Na primeira passagem, do final da Introdução à $K r V$, ele pensa a primeira Crítica à maneira de um organismo, mais especificamente de uma árvore, com troncos e raiz. A partir da anunciada divisão do conhecimento nos elementos do entendimento e da sensibilidade, ele escreve:

Como introdução ou advertência parece necessário dizer apenas que há dois troncos do conhecimento humano, que talvez brotem de uma raiz comum, mas desconhecida a nós, a saber, sensibilidade e entendimento: pela primeira, objetos são-nos dados, mas pelo segundo eles são pensados. (KrVB 29)

Comparemos com essa passagem a primeira frase da Introdução à Lógica Transcendental:

Nosso conhecimento surge de duas fontes principais do ânimo [Gemüt], cuja primeira é receber as representações (a receptividade das impressões) e a segunda, a faculdade de conhecer um objeto por estas representações (espontaneidade dos conceitos); pela primeira um objeto nos é dado, pela segunda é pensado em relação com essas representações (como simples determinação do ânimo). (KrV A 74)

2 KANT, I. Crítica da razão pura. Tradução de Valerio Rohden e Udo Baldur Moosburger. São Paulo: Abril, 1980. (Coleção Os Pensadores).

3 KANT, I. Crítica da faculdade do juízo. Tradução de Valerio Rohden e António Marques. Rio de Janeiro: Forense Universitária, 1993. (1790, 2. ed. 1793, abrev.: KU). A mesma tradução, com pequena adequação idiomática, foi também editada em Lisboa (Imprensa Nacional/Casa da Moeda, 1992).

4 Cf. ROHDEN, V. El término Gemüt en la Crítica del Juicio. In: SOBREVILLA, D. Filosofia, política y estética en la Crítica del Juicio de Kant. Lima: Goethe-Institut, 1991. p. 49-64. Cf. tb. a edição brasileira, com algumas modificações: O sentido do termo Gemüt em Kant. Analytica, Rio de Janeiro, v. 1, n. 1, p. 61-76, 1993, bem como a nota 20 na trad. bras. da KU, p. 48. 
Portanto, as citações referem-se ao conhecimento humano. Na primeira determinação, esse conhecimento é constituído de dois troncos e de uma raiz talvez comum, mas desconhecida. Mediante seu empreendimento de fundamentação crítica de um conhecimento objetivo finito, limitado aos juízos de experiência, Kant é muito cuidadoso em não ultrapassar esses limites criticamente estabelecidos. Ele frustra as pretensões desmedidas da metafísica especulativa, que anda com uma perna só: do tronco do entendimento, do pensar, dos conceitos, desprovido da sensibilidade, das intuições, às quais teria de se aplicar. O Idealismo alemão, partindo de Kant, transgrediu mais uma vez esses limites, cujo equivalente racionalismo anterior Kant procurara criticar e corrigir. Os idealistas tentaram apresentar sem véu as profundezas da alma, a cujo respeito Kant nos oferece uma passagem semelhante às duas primeiras, na doutrina do Esquematismo:

Este esquematismo de nosso entendimento é uma arte oculta nas profundezas da alma humana, cujo verdadeiro manejo dificilmente arrebataremos algum dia à natureza, de modo a poder apresentá-la sem véu. ( $K r V$ B 180-1)

Na segunda citação Kant, em vez do tronco, fala de duas fontes do ânimo. $\mathrm{O}$ ânimo seria esse elemento comum às duas fontes, da receptividade e da espontaneidade. É claro, no texto não está dito, mas para elas se combinarem entre si não apenas acidentalmente, receptividade e espontaneidade teriam de ser destinadas uma à outra pelo ânimo, ou seja, ter-se-ia de admitir certa unidade originante e enfim um todo, ao qual essas fontes do conhecimento se destinam e com vistas ao qual se articulam.

E, para completar minhas primeiras observações, chamaria a atenção para a referida comparação do esquematismo com uma arte oculta nas profundezas da alma humana. Vejam que Kant não é dogmático; ele é crítico, não faz afirmações e negações sem base. Na primeira citação ele falou em "talvez", aqui ele fala de "dificilmente". Portanto, trata-se aí de um segredo guardado pela natureza no fundo da alma, coberto por um véu. Os esquemas ligam categorias às condições dos fenômenos, espaço e tempo, na produção do conhecimento. Essa parte vem tratada no contexto de uma doutrina transcendental da capacidade de julgar, entendida como faculdade de subsumir sob regras ou de ligar o geral e o particular.

Outro lado desta minha introdução tem a ver com o importante livro de Bernd Dörflinger, $A$ vida da razão teórica. ${ }^{5} \mathrm{Na}$ primeira parte do livro, o autor 
aborda o conceito de vida como ideia-guia. Na segunda, trata das formas da intuição, e, na terceira, do entendimento. Portanto, com uma estrutura bastante simples, ele, por assim dizer, desdobra o que vimos ou sugerimos até aqui, com a diferença de que, em vez do termo Gemüt, aparece no livro o termo Leben (vida), à qual remetem agora os troncos da sensibilidade e do entendimento. Logo, relacionam-se aí conhecimento e vida.

A relação entre conhecimento e vida justifica-se pelo que foi dito, porque na $K r V$ oculta-se a representação do conhecimento como dando-se dentro de um organismo que envolve uma representação sistemática e articulada das partes em um todo dotado de vida. O conhecimento constitui-se pela vida da razão teórica. Ora, diz-nos a Metafísica dos costumes (abrev.: MS), vida é "a faculdade de um ente de agir conformemente a suas representações". ${ }^{6}$ Logo, isto significa que a vida teórica envolve uma representação prática de como se age no nível teórico, na busca de seu fim próprio. A teoria da finalidade, já presente nas últimas seções da $K r V$ como ponto de convergência sistemático de tudo o que foi antes considerado, é propriamente desenvolvida na terceira Crítica. Segundo esta, o que caracteriza tanto a beleza quanto o organismo é uma finalidade dinâmica subjacente. Ora, se na $K r V$ tudo é convergência e síntese de faculdades de intuições e conceitos, se a $\mathrm{KrV}$ é um sistema guiado por uma ideia de finalidade, então o sistema teórico é dotado de vida. O todo é representado mediante uma ideia da razão. Portanto a razão, como terceira faculdade além de entendimento e sensibilidade, é aquela que se representa criticamente um todo da razão pura, que enquanto um organismo é guiado por uma ideia de unidade que anima ou vivifica o sistema. $\mathrm{O}$ grande artista da vida vai ser o juízo, como faculdade intermediária entre as faculdades de conhecer superiores, entendimento e razão, e que é também a faculdade mediadora do ânimo entre as faculdades de conhecer e apetecer, entre teoria e prática.

Há duas funções da faculdade de julgar: uma consiste em determinar, subsumindo o particular sob o universal dado; e a outra, em refletir, isto é, em comparar representações empíricas em vista de um universal não dado. As reflexões estéticas e teleológicas restringem-se ao exercício desse segundo tipo de faculdade de julgar. Na faculdade de julgar reflexiva, o conceito representa um todo vivido e não dado. Por isso Kant dirá que o belo se expressa através de uma conformidade a fins sem fim; o fim ou o conceito não é dado, ele é pensado como ideia inteligível. A Estética interessa-se pela forma, sem preocupação com a determinação da matéria: por exemplo, quando vejo uma 
mulher andando, não determino esteticamente o fim que ela busca, embora este fim exista, mas aprecio apenas a forma de seu movimento, e esta apreciação gera prazer como sentimento de vida.

Prazer e sentimento de vida equivalem-se. Vou citar a respeito a passagem em que Kant diferencia entre, por um lado, a apreensão cognitiva de um edifício regular e conforme a fins, e, por outro, a consciência dessa representação com a sensação de complacência ou prazer. No caso do conhecimento, a representação é referida ao objeto e tem de concordar com ele; e, no caso da experiência estética, a representação é referida ao sujeito, concordando (ou não) com seu sentimento de vida:

Aqui a representação é referida inteiramente ao sujeito e na verdade ao seu sentimento e vida, sob o nome de sentimento de prazer ou desprazer, o qual funda uma faculdade de distinção e ajuizamento inteiramente peculiar, que em nada contribui para o conhecimento, mas somente mantém a representação dada no sujeito em relação com a inteira faculdade de representações, da qual o ânimo torna-se consciente no sentimento de seu estado. (KU B 4-5, AA 204)

Sobre a identidade de vida e prazer vale lembrar a declaração enfática de Kant, na Reflexão 4857, datada de 1776-78: "Unicamente prazer e desprazer constituem o absoluto, porque eles são a própria vida". Mas existe uma segunda parte na frase destacada antes, que contém a chave para a explicação desse sentimento. O sentimento de vida é um sentimento concernente ao todo, ao todo do mundo em que vivemos, é um sentir-se bem no todo do mundo ou em relação a um todo humano. O texto remete ao Gemüt como a inteira faculdade de representações, e diz que o ânimo, que sente a beleza ou o prazer no sentimento de seu estado, tem um sentimento em relação ao todo da faculdade de representações. A presença desse todo é denunciada no prefixo Ge, do Gemüt. Mut, além de seu sentido usual de coragem, significa aqui faculdade. Gemüt significa então o todo das faculdades representativas. ${ }^{7}$ Então o importante nisso é que o sentimento estético e o juízo estético remetem a um todo vivido. O juízo sobre o belo e o feio remete a um todo, como se o mundo inteiro se impregnasse da minha apreciação da beleza de um objeto singular, efêmero, como se para poder ver beleza numa flor esse sentimento extravasasse como um sentimento em relação ao todo ao qual o sentimento da flor se liga, ou seja, a uma presumível concordância universal de todos com ele e com o universal sentimento de vida.

7 Há vários termos em que essa relação com o todo mediante o prefixo Ge pode ser vista, por exemplo, em Berg $=$ monte e Gebirge = cordilheira, Stern = estrela e Gestirn = constelação. 
Porém, o que está por trás da beleza e do organismo é, nessa virtualidade mesma, uma ideia. O conceito e a determinação que faltam nessa vivência subjetiva e intersubjetiva são preenchidos pela vivência de uma ideia, como uma possibilidade de vida em relação ao todo da vida e da humanidade. O gênio, que é o artista por excelência, seja ele pintor, poeta, músico, escultor, comunica na forma de sua obra de arte uma ideia, ou seja, comunica algo inacessível à determinação intelectual e que se expressa numa linguagem simbólica ou analógica.

Para encerrar estas primeiras considerações, cito a propósito uma passagem de Otfried Höffe, que confirma minha interpretação:

Enquanto os fenômenos deixam constatar-se empiricamente (eles formam o particular dado), a suposição da totalidade conforme a fins não surge da experiência. A totalidade conforme a fins é o universal não dado, que a faculdade de julgar descobre por espontaneidade própria. Assim em juízos de conformidade a fins, o dar-se sensível, a natureza e o ato de pôr espontâneo, a liberdade, formam uma unidade originária. (HÖFFE, O. Immanuel Kant. São Paulo: Martins Fontes, 2005. p. 295)

Quero com isso dizer que também o sistema teórico forma um todo articulado como um organismo. Logo, ele é dirigido por uma ideia, que obviamente não é tematizada, porque na Analítica da $K r V$ é dada prioridade à compreensão minuciosa das partes. Contudo, se entendimento e sensibilidade estão reciprocamente destinados na formação do conhecimento, se inclusive há um "eu penso" que acompanha todas as representações, se a própria definição de juízo em sentido teórico remete à apercepção originária, se é verdade que as representações formam um todo no Ge-müt, de tal modo que revelem um parentesco, isto é, uma afinidade, então a $K r V$ pode ser entendida transcendentalmente na perspectiva do Gemüt como Ge-müt, ou seja, como um todo de faculdades em relação recíproca, sob o primado da razão e sob a mediação do juízo. Então o Gemüt representa as três Críticas de Kant: ele é exatamente o conjunto das faculdades que se apresentam nas respectivas três Críticas.

Vejamos esta questão do parentesco ou da afinidade entre as faculdades. A Antropologia em sentido pragmático assim define a Verwandschaft (afinidade):

Entendo por Verwandschaft (parentesco, afinidade) a reunião a partir da proveniência do múltiplo de um fundamento [Ich verstehe unter der Verwandschaft die Vereinigung aus der Abstammund des Mannigfaltigen von einem Grunde]. ${ }^{8}$ 
Assim o múltiplo revela uma afinidade, se é gerado desde um mesmo fundamento. ${ }^{9}$ E assim o conhecimento é o terceiro que resulta da reunião de duas desigualdades, entendimento e sensibilidade, como se uma nascesse da relação com a outra, mas em verdade como se ambas se originassem de uma raiz comum. O que para nós é inteiramente incompreensível, ou seja, que duas matérias desiguais pudessem nascer de uma mesma raiz. ${ }^{10}$ Assim, no caso do conhecimento ou em outros casos, é possível que a articulação tenha em vista que por ela seja propiciado o desenvolvimento de cada parte, embora fazendo supor uma raiz, ou um germe, ou uma razão seminal comum.

A $K r V$ explica a Verwandschaft como situada entre a multiplicidade e a unidade, as quais são princípios da unidade sistemática, que representadas em seu máximo desenvolvimento chamam-se ideias. A razão procura a unidade da experiência segundo ideias. O múltiplo revela uma afinidade, sob o princípio da unidade, das coisas, das suas propriedades e forças. Kant aplica esse princípio para explicar as diferentes trajetórias dos planetas, uns em círculo, outros em elipse, outros se afastando de Sol a Sol, e que são entendidos como partes de um sistema cósmico ilimitado, mantido sob uma e mesma fonte motora (cf. $K r V$ B 690 et seq.).

Trata-se de princípios heurísticos. A ideia de um maximum é um analogon de um esquema para a representação da unidade sistemática universal dos conceitos do entendimento (mediante o abandono de condições restritivas, de uma multiplicidade indeterminada). Essa ideia serve de regra ou princípio de unidade sistemática de todo o uso do entendimento, para que o seu uso empírico e determinado na experiência concorde universalmente consigo mesmo. Tratase de princípios subjetivos (máximas da razão) que não determinam objetos, mas explicitam interesses da razão.

Gostaria de chamar a atenção sobre como a $K U$ apresenta em termos de Gemüt a articulação entre dois domínios da faculdade de conhecimento, relativos aos conceitos de natureza e de liberdade. O entendimento é a faculdade de legislar teoricamente mediante conceitos de natureza. A razão é

9 Por exemplo, Kant propunha para a conversação à mesa em torno de um tema a observância do parentesco ou da afinidade entre o que é falado, até que se esgotasse o tema ou se anunciasse uma pausa a seu respeito. O termo latino correspondente affinitas teve amplo uso na Química do século 18, onde duas matérias diferentes se atraem ou se repelem, produzindo um terceiro ou também uma eventual exclusão de um terceiro, etc. Cf. ROHDEN, V. A dupla analogia, de Kant e Goethe, com um experimento químico. In: SILVA, João Carlos Pires da. Plenárias da ANPOF 2004/2006. Salvador: Quarteto/ANPOF, 2006. p. 225-238.

10 Kant defende uma teoria da atração diferente do provérbio latino: Similis simili gaudetur, - por exemplo, de que, no caso de enamorados ou casais, o assemelhamento é apenas uma consequência, e não a causa da união. A natureza age aí instintivamente, no sentido de que sujeitos diferentes se atraiam para que floresça a multiplicidade. 
a faculdade de legislar praticamente mediante conceitos de liberdade. Ambas as faculdades legislam no mesmo território da experiência, sem que uma invada a seara da outra (cf. $K U$ B XVIII, $A A 175$ ). A $K r V$ mostra que as duas legislações podem conviver sem contradição no mesmo sujeito. E, para que o domínio do conceito de liberdade possa ter alguma influência sobre o domínio do conceito de natureza, tem de constituir-se alguma afinidade ou mediação entre ambos, ou seja:

A natureza tem de ser pensada de modo que a conformidade a leis da sua forma concorde pelo menos com a possibilidade dos fins que nela atuem segundo leis da liberdade. ( $K U \mathrm{~B} \mathrm{XX}, A A 176)$

A terceira Crítica encontra entre as faculdades superiores de conhecimento, que compreendem entendimento, juízo e razão, uma espécie de intermediação exercida pela faculdade do juízo, que comprova com isso um parentesco ou afinidade entre elas. Mas em seguida Kant acrescenta que uma segunda espécie de intermediação é exercida pela faculdade do juízo, agora entre as faculdades de representação, as quais reúnem as faculdades de conhecimento, de apetição e sentimento de prazer e desprazer. O conjunto dessas últimas oferece uma importância maior que aquelas, porque entre as últimas o ânimo humano na verdade vincula todas as faculdades humanas entre si, e não apenas internamente a faculdade de conhecimento. Kant vê essa vinculação ocorrendo graças ao princípio de conformidade a fins. Trata-se de um conceito só para refletir sobre o conceito de natureza e poder pensar as leis empíricas particulares segundo uma unidade que torna possível um sistema. Essa conformidade a fins é atribuída pela faculdade de julgar à natureza, como conformidade a fins transcendental, sem cuja pressuposição não teríamos ordem no fio condutor para uma investigação e tampouco experiência de leis empíricas em sua multiplicidade. Sem essa colaboração do juízo reflexivo, o entendimento não poderia constituir uma experiência articulada. $\mathrm{O}$ entendimento pensa um princípio como o da "lei de especificação da natureza", para progredir na experiência e adquirir conhecimento. A parte estética da $K U$ é a essencial (B L, $A A$ 193), porque é nela que se encontra o princípio a priori para refletir sobre a natureza. A percepção refletida de um prazer encontra seu fundamento na condição ainda que subjetiva dos juízos reflexivos — "na concordância conforme a fins de um objeto... com a relação das faculdades de conhecimento entre si” (KU B XLVII, $A A$ 191). Mais adiante é dito que o fundamento desse prazer encontra-se no acordo espontâneo das faculdades de conhecimento em jogo entre si.

Para retornar à $K r V$, verificamos que as faculdades geradoras do conhecimento, entendimento e sensibilidade, estão espontaneamente destinadas 
umas às outras, fundadas numa raiz comum de origem desconhecida. Sua intermediação pelo juízo faz pensá-las tanto como articulação determinante entre o geral e o particular mediante esquemas, quanto como faculdade de julgar reflexiva, que mediante o prazer na conformidade a fins as vincula com o todo do Gemüt, do mundo e da vida, que é base, como vimos, do juízo de reflexão. A representação articulada das partes num todo dá-se mediante a representação de um fim como ideia, para a qual converge dinamicamente a $K r V$. Vejamos essa seção da Introdução à $K r V$, que trata da ideia e divisão da $K r V$, e que culmina na representação orgânica da articulação de entendimento e sensibilidade com uma presumível raiz comum.

Kant afirma aí que o mínimo que podemos fazer é "encarar uma ciência da simples avaliação da razão pura, das suas fontes e limites, com a propedêutica da razão pura" ( $K r V$ B 25). Como tal ela não é idêntica a uma filosofia transcendental, que conteria todo o conhecimento analítico e sintético, porque a $K r V$ limita-se a "compreender os princípios da síntese a priori em toda a sua extensão" e valor - como uma crítica transcendental da faculdade da razão. A $\mathrm{KrV}$ somente projeta arquitetonicamente o plano completo da ideia da filosofia transcendental, e não é um sistema completo. Essa obra, contudo, promove uma enumeração completa dos conceitos primitivos do conhecimento puro [das categorias], sem uma análise completa dos mesmos, até porque o fim da inteira crítica é a síntese (cf. $K r V$ B 28). A $K r V$ é a ideia completa de uma filosofia transcendental, mas com o propósito apenas da avaliação completa do conhecimento sintético a priori. Isso é dito depois de ela reduzir-se a observar que a divisão dessa ciência desde o ponto de vista de um sistema geral deve conter uma doutrina dos elementos e uma doutrina do método, com suas respectivas subdivisões, sem expor aí suas razões. E é aí que, como única antecipação, Kant faz a observação, que tem de ser, portanto, para ele a mais importante: "Como introdução ou advertência parece necessário dizer apenas que há dois troncos do conhecimento humano, que talvez brotem de uma raiz comum, mas desconhecida a nós, a saber, sensibilidade e entendimento..." (KrV B 29).

Entendo que essa raiz comum deve ser buscada no próprio Gemüt, além do qual, diz-nos a $K U$, não nos é permitido ir. O Gemüt oferece-nos a razão para pensá-lo transcendentalmente como a condição de possibilidade última do conhecimento humano, pois: primeiro, já terminologicamente o Gemüt expressa um todo unitário de faculdades cognitivas e representativas; segundo, o juízo apresenta-se no nível das faculdades de conhecimento superiores como o termo médio da ligação; terceiro, também no nível da relação entre entendimento e sensibilidade ele possibilita mediante a teoria do esquematismo a aplicação 
do geral ao particular ou dos princípios à experiência; quarto, igualmente no nível das faculdades representativas gerais o juízo de reflexão exerce uma função ainda mais importante, pondo em relação, mediante o sentimento de prazer/desprazer, as faculdades cognitivas e a faculdade apetitiva. É mediante o conceito de conformidade a fins que o juízo dá unidade sistemática às leis empíricas particulares. Quinto, no $\S 19$ da $K r V$ o juízo é definido do seguinte modo: "Um juízo não é senão o modo de levar conhecimentos dados à unidade objetiva da apercepção" (KrV B 141-2). Esta remissão de um juízo à autoconsciência como condição de sua objetividade leva à compreensão dos juízos de experiência como sistema do conhecimento objetivo, do qual o juízo acima definido é o mediador.

Com isso não quero, na verdade, dizer que na intuição empírica tais sínteses das intuições pertencem umas às outras, mas que na síntese das intuições pertencem umas às outras em virtude da unidade necessária da apercepção, isto é, segundo princípios da determinação objetiva de todas as representações, na medida em que disso possa resultar um conhecimento, princípios derivados todos da unidade transcendental da apercepção. (KrV B 142)

Sexto, ora, se existe um sistema do conhecimento objetivo mediante a reflexão do juízo determinante, que remete à autoconsciência como fonte da unidade necessária da experiência, então, tem-se que pensar também o sistema do conhecimento, como todo sistema, sobre a base de uma ideia.

Para tornar isto mais claro, vejamos brevemente o significado da noção kantiana de sistema. O conhecimento comum, para transformar-se em ciência, tem de abandonar o mero agregado de conhecimentos e passar a uma unidade sistemática. Kant define o sistema como unificação de vários conhecimentos sob uma ideia: "Por sistema compreendo a unidade dos múltiplos conhecimentos sob uma ideia" ( $K r V$ B 860). A ideia define-se como o conceito racional da forma de um todo, em que a posição das partes em relação recíproca é determinada a priori, contendo o fim e a forma do todo. É, pois, um todo articulado, crescendo desde dentro e não por adição de membros.

Que a razão e todos os conhecimentos articulados entre si existem sob a forma de um organismo vivo, vêmo-lo no ulterior desenvolvimento destas considerações. O esquema decorrente de uma ideia, isto é, em parte racional e em parte sensível, funda uma unidade arquitetônica devida à afinidade (Verwandschaft) das partes e à sua derivação de um único fim interno. Vejam que o fim é interno, logo, o organismo sob o princípio da razão desenvolvese, dentro do próprio organismo, autonomamente. A ideia de uma ciência encontra-se na razão sob a forma de um germe, em que todas as suas partes estão ocultas (cf. $K r V$ B 862). Por isso uma ciência não deve ser explicada e 
determinada pela descrição de seu autor, unindo naturalmente as partes, mas segundo a ideia fundada na própria razão. Pois as ciências são concebidas a partir de um certo interesse universal. O próprio autor e os pósteros não o identificam logo. Isso constitui, segundo Kant, um infortúnio, ou seja, que só depois de muito tempo apenas vislumbramos a ideia com uma luz um pouco mais clara. Mesmo que seja assim, que a ciência pareça nascer sob a forma de uma generatio aequivoca, ainda assim todos os conceitos "possuíam, como um germe originário, o seu esquema na razão, a qual simplesmente se desenvolve" ( $K r V$ 863), — portanto, a razão é um organismo! Cada sistema (digamos, o sistema teórico, o sistema prático, o sistema estético) está articulado segundo uma ideia. Mas o conhecimento humano parece ser o grande sistema em que todos os sistemas se articulam entre si:

Consequentemente, não só cada sistema está por si articulado segundo uma ideia, mas também todos eles estão por sua vez unidos finalisticamente entre si, como membros de um todo, num sistema do conhecimento humano. (KrV B 863)

Não nos iludamos! Se o conhecimento humano é o sistema que articula finalisticamente todos os sistemas entre si, isso em verdade ocorre pela ideia de um fim universal da razão, que já em cada ciência envolvia um interesse humano universal. Portanto, Kant estabelecerá um fim prático do conhecimento, fundado em suas ideias mestras, as de vida e de liberdade, e entende esta como vida originária. Ele volta aqui, no terceiro capítulo da Doutrina do Método, à ideia de raiz comum. E agora sabemos o que Kant tinha em mente ao falar do conhecimento como um organismo ou como uma árvore. Ele diz agora: "Limitar-nos-emos a começar partindo do ponto em que a raiz comum de toda a nossa capacidade de conhecimento se bifurca em dois troncos, dos quais um é a razão" ( $K r V$ B 863). Kant explica que entende aí por razão a inteira faculdade superior de conhecimento, portanto, incluindo entendimento e juízo, e contrapondo-a ao empírico.

A Filosofia, como filosofar, como "simples ideia de uma ciência possível que não é dada em parte alguma" ( $K r V$ B 866), diferentemente da unidade sistemática ao modo da perfeição lógica do conhecimento, busca no arquétipo do filósofo uma "ciência como referência de todo o conhecimento aos fins essenciais da razão humana" ( $K r V$ B 867). A Filosofia prescreve, segundo seu conceito cósmico, uma unidade sistemática a partir do ponto de vista dos fins. Nem todos os fins essenciais são um fim supremo, que é único. Este fim terminal (Endzweck) é a inteira destinação do homem, cuja filosofia chama-se Moral. Pelo $§ 84$ da $K U$ sabemos que o Endzweck difere de letzter Zweck (fim último), por ser aquele um fim para si mesmo, o homem como ser moral livre. 
Filósofo então em sentido estrito é, desde os Antigos, o filósofo moral. Mas já na $K r V$ Kant vai dizer que os dois objetos da legislação da razão humana, natureza e liberdade, tratados em dois sistemas separados, terminam num só sistema filosófico. Crítica e metafísica podem entender-se universalmente como conhecimento filosófico estrito. E a doutrina moral - a única conformidade a ações derivada de modo totalmente a priori de princípios - é também um tronco especial do conhecimento humano. Com isso superamos aqui aquele modo binário de dois troncos, entendimento e sensibilidade, e acrescentamos legitimamente o tronco da razão a um conceito mais elaborado de conhecimento, perfazendo um sistema teórico fundado praticamente desde dentro. Não obstante a divisão do sistema da metafísica em quatro partes (ver $K r V$ B 874-5), filosofia em sentido estrito são a Metafísica da natureza, a Metafísica dos costumes e, principalmente, a Crítica da razão (cf. B 878).

\section{À guisa de conclusão}

Para que nos encaminhemos a uma conclusão, gostaria de considerar três aspectos:

1. Da relação entre conhecimento e vida na $K r V$, a partir da perspectiva de Dörflinger.

2. Da redução das três perguntas fundamentais a uma quarta, na Lógica.

3. Da aplicação de uma frase de Goethe em Fausto I.

Primeiro, segundo Dörflinger, a razão teórica é vista por Kant no Prefácio à $2^{\mathrm{a}}$ ed. da $K r V$ como uma unidade autossubsistente, em que tudo é membro e cada um inter-relacionado aos demais. Esta é a passagem da $K r V$ que inspira o livro de Dörflinger, Das Leben theoretischer Vernunft, também citada acima como epígrafe:

Com referência aos princípios do conhecimento, a razão especulativa pura é uma unidade que subsiste por si de um modo bem peculiar e na qual, como um corpo organizado, cada membro existe em função de todos os demais e todos os demais em função dele, e assim nenhum princípio pode ser tomado com segurança numa relação sem ter sido ao mesmo tempo investigado na sua relação universal com todo o uso puro da razão. (KrV B XXXIII)

Como o conceito de organismo, que guia essa investigação, funda-se no conceito de vida, pode-se antever a partir daí a relação da primeira Crítica com a terceira Crítica. De acordo com esta concepção, a razão teórica em sua universalidade assenta num Selbst (si mesmo) idêntico, enquanto unidade com 
uma pluralidade de princípios de conhecimento como membros. O si mesmo (Selbst) é visível como uma espécie de ponto central, em relação ao qual os membros obtêm sua interconexão num todo que os integra (DÖRFLINGER, p. 7). E, por último, a razão teórica, mediante o conceito de fim inerente a um ser vivo, revela a sua praticidade. A ideia de sistema deixa de ser meramente reguladora, para assumir uma função fundante com vista aos princípios constitutivos do conhecimento. Esses princípios não são encontrados, mas são reflexivamente desenvolvidos conformemente à forma de um todo ativo como ideia. Essencial a um organismo vivo é que ele se desenvolva a partir de dentro, não por acréscimo de novos membros, mas cada um buscando o seu fim articuladamente. O organismo é um analogon da razão, em que esta não é entendida biologicamente, e sim a Biologia é pensada por analogia com a racionalidade (cf. DÖRFLINGER, p. 31). Enfim, sobre a complementaridade dos dois troncos do conhecimento cito ainda uma vez Dörflinger:

A espontaneidade já não deve restringir-se ao sujeito intelectual, e caracteriza de modo igual o sujeito que, por suas formas de intuição, dispõe-se para um intuir. Com essa comunidade $<$ Gemeinsamkeit $>$ cumpriu-se uma exigência essencial da pretensão sistêmica da $K r V$ formulada a partir do interesse arquitetônico da razão, segundo cuja pretensão não se pode, em relação aos princípios do conhecimento, ficar parado nos troncos separados de espontaneidade e receptividade. (DÖRFLINGER, p. 98)

Trata-se aí, segundo Dörflinger, de buscar uma "espontaneidade primordial como fundamento da unidade de uma interconexão sistemática de ações cognitivas".

Quero acrescentar, em segundo lugar, que, se pensarmos que o ânimo (Gemüt) não apenas funda a possibilidade transcendental das três perguntas básicas da $\mathrm{KrV}$ - que posso conhecer, que devo fazer, que me é lícito esperar $(K r V$ B 833) - mas que, na medida em que a Lógica acrescenta às três perguntas uma quarta — que é o homem —, poderíamos dizer que o Gemüt nas sua diversas funções representativas, tratadas nas três Críticas em que aquelas perguntas são respondidas, corresponde ao homem, que se coloca a questão última a si mesmo, e assim constitui segundo Tugendhat a base moderna de uma Antropologia filosófica como filosofia primeira. ${ }^{11}$ Portanto, na medida em que o Gemüt é admitido por Kant como o princípio da vida, nesta medida a sua filosofia realiza-se nesse desenvolvimento interno e autoconsciente do Gemüt como uma teoria da vida.

11 Cf. TUGENDHAT, E. Antropologia filosófica como filosofia primeira. In: POMMER, A.; FRAGA, P. D.; SCHNEIDER, P. R. Filosofia crítica. Festschrift pelos 50 anos do Curso de Filosofia da Unijuí. ljuí: Ed. UNIJUÍ, 2007. p. 183-199. 
Em terceiro lugar, Kant admitiu que o conhecimento, por ocasião de seu nascimento, relaciona-se com o prazer, que segundo ele corresponde ao sentimento de vida, perdendo-se posteriormente de vista essa relação:

$\mathrm{Na}$ verdade, nós já não sentimos mais qualquer prazer notável ao apreendermos a natureza e a sua unidade da divisão em gêneros e espécies, mediante o que, apenas são possíveis conceitos empíricos, pelos quais a conhecemos segundo as suas leis particulares. Mas certamente esse prazer já existiu noutros tempos, e somente porque a experiência mais comum não seria possível sem ele, foi-se gradualmente misturando com o mero conhecimento sem se tornar mais especialmente notado. ( $K U$ B XL, $A A$ 187)

O que quero, pois, propor no conjunto desta apresentação é que se vá ao encontro dessa advertência de Kant, da conexão entre conhecimento e prazer, e assim se dê um novo sentido à frase dicotômica de Goethe:

Cinzenta, caro amigo, é toda teoria

E verde a árvore dourada da vida.

- Grau, teurer Freund, ist alle Theorie

Und grün des Lebens goldner Baum. ${ }^{12}$

De acordo com o que vimos até aqui, eu diria a propósito dessa frase do grande leitor de Kant que foi Goethe: a teoria é cinzenta, se ela perdeu a relação com a vida. Nesta medida ela se banaliza e burocratiza, e deixa de ser criativa. Na medida em que, contrariamente, quiser manter a sua criatividade, que envolve uma relação da teoria com o prazer de conhecer, nessa medida poderemos dizer que a teoria deixa de ser cinzenta. E o conhecimento, pensado na Crítica da razão pura em analogia com uma árvore, passará então a reconhecer-se como a árvore dourada do conhecimento.

Se, pois, o sentimento de vida "mantém a representação dada no sujeito em relação com a inteira faculdade de representações, da qual o ânimo tornase consciente no sentimento de seu estado" (KU B 5, AA 204), então também acredito que reuni aqui os elementos principais para, a partir do conceito de Gemüt, provar a possibilidade do conhecimento em articulação orgânica com o conceito de vida, já internamente à Crítica da razão pura. 
ANEXO

Quadro das faculdades representativas do ânimo ${ }^{13}$

\begin{tabular}{|c|c|c|c|}
\hline $\begin{array}{c}\text { FACULDADES } \\
\text { GERAIS DO } \\
\text { ÂNIMO }\end{array}$ & $\begin{array}{c}\text { Faculdades de } \\
\text { conhecimento }\end{array}$ & Princípios a priori & Aplicação a \\
\hline $\begin{array}{c}\text { Faculdade de } \\
\text { conhecimento }\end{array}$ & Entendimento & Conformidade a leis & Natureza \\
\hline $\begin{array}{c}\text { Sentimento de prazer } \\
\text { e desprazer }\end{array}$ & Faculdade do juízo & Conformidade a fins & Arte \\
\hline $\begin{array}{c}\text { Faculdade de } \\
\text { apetição }\end{array}$ & Razão & Fim terminal & Liberdade \\
\hline
\end{tabular}

